ORIGINAL ARTICLE

\title{
Comparative Study of Intrathecal Low Dose Bupivacaine and Fentanyl Versus Conventional Dose of Hyperbaric Bupivacaine for Cesarean Section
}

\author{
*MS Hossain ${ }^{1}$, MS Islam², S Abbasi ${ }^{3}$ \\ ABSTRACT
}

Background: Pregnancy and childbirth related complications are the leading causes of maternal mortality and morbidity in Bangladesh. An estimate shows that about 28,000 mothers die in each year in Bangladesh due to obstetric complications. The aim of this study was to find out the birth practice among rural women in Bangladesh.

Material and Methods: This descriptive cross sectional study was carried out among 1220 respondents by purposive sampling technique from July 2016 to June 2017 in different Private Hospital, Dhaka. Data were collected by a structured questionnaire duly pretested through face to face interview. Data were analyzed manually and by using computer.

Results: Then study revealed that majority of the respondents $80 \%$ were Muslims by religion and about

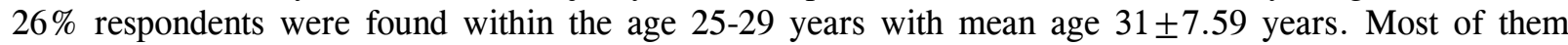
$86 \%$ were literate and only $14 \%$ were found illiterate. Among the respondents $75 \%$ were Housewives and $11 \%, 9 \%, 1 \%$ and $4 \%$ were involved in Service, Business, Agriculture and others occupation respectively. Moreover, $78 \%$ respondents monthly income were less than TK 3000. About $43 \%$ \& $16 \%$ respondents were found to have $2 \& 3$ children respectively. In this study, about $73 \%$ received antenatal visit and among them 57\% received 1 to 3 antenatal visits and 74\% received TT immunizations. It was found that $69 \%, 54 \%$ and $59 \%$ received antenatal advices on healthy diet, personal hygiene, drug use respectively. Home delivery and Hospital delivery practice were found among $44 \%$ \& $56 \%$ respondents respectively. The reasons for home delivery like Feeling comfortable, Family decision and Financial problem were found in $60 \%, 26 \% \& 42 \%$ respondents respectively. The most common complications during last delivery were obstructed labor, found among $39 \%$ respondents.

Conclusion: Still now women prefer home delivery. Major reasons for home delivery were Feeling comfortable, Family decisions and Financial problems. Delivery conduction by qualified doctors were found only among $47 \%$ women. Efforts needed to increase maternal health related knowledge and awareness towards birth practice to facilitate decision in minimizing complications and mortality.

Key Words: Birth Practice, Maternal Health, Bupivacaine, Fentanyl, Cesarean Section

\section{Introduction}

The choice of anesthesia for cesarean section is determined by multiple factors, including the indication for operative delivery, its urgency, patient and obstetrician preference and skill of anesthetists. Regional anesthesia has a number of

advantages including less neonatal exposure to potentially depressant drugs, decreased risk of maternal pulmonary aspiration, an awake mother at the birth of her child. There is option of using spinal opioid for postoperative pain relief. ${ }^{1}$ The intrathecal

\footnotetext{
$1 *$ Dr. Muhammad Sazzad Hossain, Associate professor, Department of anesthesiology, National Institute of ENT Tejgaon, Dhaka, Bangladesh

${ }^{2}$ Dr. Md. Sirajul Islam, Assistant Professor, Department of Anesthesiology, Anwer Khan Modern Medical College, Dhaka, Bangladesh

${ }^{3}$ Dr. Sharmin Abbasi, Assistant Professor, Gynaecology and Obstetrics, Anwer Khan Modern Medical College Dhaka, Bangladesh
}

*Corresponding author

Date of submission: 11.11.2017, Date of acceptance: 15.12 .2017 
(spinal) anesthesia has some complications like hypotension, post-dural puncture headache etc. Drug used mainly hyperbaric bupivacaine 10 to 15 mg with or without fentanyl 10 to 25 micrograms ${ }^{1,2}$. Spinal anesthesia is the most common method of regional block in cesarean section ${ }^{3}$. Many physiological and anatomical changes during pregnancy affect spinal anesthesia. The hormonal and mechanical factors make pregnant women require less local anesthetic than non-pregnant women to attain the same level of spinal anesthesia ${ }^{4}$. They stand at a greater risk of toxicity to local anesthetics due to the increased penetration through tissue membranes, decreased plasma protein binding and progesterone enhanced cardiotoxicity ${ }^{5}$. Any dose alterations can cause hemodynamic instability leading to increased maternal and neonatal morbidity and mortality. Studies on hemodynamic alterations in spinal anesthesia show that the hypotension after spinal anesthesia is caused due to the enhanced sympathetic segmental block due to higher dose of local anesthetic ${ }^{6}$. Among the local anesthetics hyperbaric bupivacaine is the preferred local anesthetic. The unique characteristics of this drug are the highest potency, slow onset of action (5- 8min) and longer duration of action. Further, studies have shown that the combination of bupivacaine and fentanyl produce less hypotension ${ }^{7}$. Studies have also shown that by adding intrathecal opioids to bupivacaine in cesarean section enhance the quality of surgical analgesia ${ }^{8}$. The opioids act on opioid receptors present in the substantia gelatinosa of dorsal horn of spinal cord. They are commonly used as additive with local anesthetics for potentiating their effects, thus offering hemodynamic stability by reducing the dose and side effects of local anesthetics. They also prolong the duration of postoperative analgesia ${ }^{9}$. Among the synthetic opioids, fentanyl is favorable due to greater potency, faster onset of action and rapid redistribution with an associated decrease in the plasma concentration of the drug ${ }^{10}$. The aim of this study was to compare and determine the efficacy of intrathecal fentanyl as an adjuvant to bupivacaine in cesarean section.

\section{Methods}

From July 2016 to June 2017, at different private hospital in Dhaka, 80 female patients with written informed consent posted for elective cesarean section deliveries under spinal anesthesia were enrolled in this study.

Inclusion criteria: ASA physical status I and II with normal coagulation profile, age between 20 to 30 years and weight 45 to $70 \mathrm{~kg}$ were enrolled in the study.

Exclusion criteria: Patients refusal, infection at the site of injection, coagulopathy, anticoagulant medication, preexisting neurological disease, uncooperative patient, musculoskeletal deformity and placenta previa were excluded in the study.

All patients were assessed clinically by general and systemic examination, airway assessment and spine examination also performed. Routine preoperative investigations done which included complete blood count, blood sugar, serum creatinine, coagulation profile, urine routine and microscopic examination and electrocardiogram.

Before proceeding with the spinal anesthesia fasting status of patient was confirmed and prophylaxis ranitidine was given. The general anesthesia machine was checked, appropriate sized endotracheal tube, laryngoscope, suction catheter and emergency drugs along with ephedrine, adrenaline and naloxone were kept ready. Intravenous access was secured with $18 \mathrm{G}$ cannula and Ringer lactate infusion was started. Pulse oximetry and noninvasive blood pressure monitors were applied

Base line systolic blood pressure (SBP), diastolic blood pressure (DBP) and pulse rate were recorded in supine position with a wedge under the right buttock Patients were allocated into two groups of 40 patients each allocation into Group I and Group II. Group I received total volume of $2.5 \mathrm{ml}$ with a combination of $10 \mathrm{mg} 0.5 \%$ hyperbaric bupivacaine and 25 microgram fentanyl, whereas Group II received $2.5 \mathrm{ml}$ with $12.5 \mathrm{mg} 0.5 \%$ hyperbaric bupivacaine. Under aseptic conditions, lumber puncture was performed with 25 gauge spinal needle 
at the level of L4-5 interspace. After the free flow of cerebro-spinal fluid the specific drug in each group was injected slowly over 20 seconds. Patients were positioned immediately in supine position. The wedge was placed under patients right buttock to avoid the supine hypotension syndrome. Oxygen was supplemented with face mask at 5 liters per minute. Systolic and diastolic blood pressure and maternal heart rate were recorded every 2 minutes for the first 30 minutes and thereafter for every 5 minutes intraoperatively. A decrease of systolic blood pressure $<95 \mathrm{~mm} \mathrm{Hg}$ or Decrease $>25 \%$ from base line was considered hypotension and treated with $5 \mathrm{mg}$ ephedrine and as required. Vasopressor requirements were noted, sensory level of block was assessed by loss of cold sensation bilaterally at 2 minutes and confirmed by a pinprick method. All patients were evaluated for quality of sensory block on a descriptive scale (good, satisfactory and poor).

Degree of motor block was assessed by modified Bromage scale as:

1. Free movement of legs and feet.

2. Just able to flex knees with free movement of feet

3. Unable to flex knees, but with free movement of feet.

4. Unable to move legs and feet.

An intraoperative pain assessment was done using visual analog scale (VAS) $(0-10 \mathrm{~cm}$ where $0=$ no pain and $10=$ worst possible pain). Postoperative pain was also assessed using VAS scale. Duration of effective analgesia was taken from the time of intrathecal injection to a VAS score $>4$. Side effects such as nausea, vomiting, pruritus and shivering were noted. Duration of two segment regressions of the sensory blocked was noted. Apgar score of newborn was recorded at 1 minute and 5 minutes.

Statistical analysis: Results were expressed as mean \pm standard deviation or number (\%). Comparison between different parameters were performed using unpaired $\mathrm{t}$ test. Comparison between categorical data was performed using chi squire test. The data was considered significant if $\mathrm{p}$ value $<0.05$.

\section{Result}

Demographic data: There was no statistical difference among groups as far as age, weight, height and duration of surgery (Table I).

Table-I: Demographic data and duration of surgery among the two groups

\begin{tabular}{lccc}
\hline & Group I & Group II & p value \\
\hline Age (years) & $23.4 \pm 2.14$ & $24.1 \pm 2.34$ & $>0.05$ \\
Weight(kg) & $56.24 \pm 3.27$ & $57.96 \pm 2.85$ & $>0.05$ \\
Height (cm) & $151.81 \pm 4.18$ & $152.32 \pm 5.07$ & $>0.05$ \\
$\begin{array}{l}\text { Duration of surgery } \\
\text { (minutes) }\end{array}$ & $48.32 \pm 6.24$ & $50.28 \pm 5.75$ & $>0.05$ \\
\hline
\end{tabular}

Sensory Blockade: Time required for the onset of sensory analgesia was comparable in both groups. Peak level of sensory analgesia was comparable in both groups $(p>0.05)$. The addition of fentanyl to bupivacaine did not change the height of block. The mean time required to reach peak sensory level was earlier in group I than group II and this was statistically significant $(p<0.05)$. The duration of effective analgesia was prolonged in group I compared to group II $(\mathrm{p}<0.05)$ and was statistically significant. These parameters are shown in Table II.

Table-II: Comparison of sensory blockade between two groups

\begin{tabular}{lccc}
\hline Parameters & Group I & Group II & p vatue \\
\hline $\begin{array}{l}\text { Time for onset of } \\
\text { sensory blocked (sec) }\end{array}$ & $65 \pm 6$ & $68 \pm 7$ & $\mathrm{p}>0.05$ \\
$\begin{array}{l}\text { Time to reach peak } \\
\text { sensory level (min) }\end{array}$ & $5.40 \pm 1.2$ & $6.72 \pm 2.1$ & $\mathrm{p}<0.05$ \\
$\begin{array}{l}\text { Time for complete } \\
\text { sensory recovery } \\
\text { (min) }\end{array}$ & $140.34 \pm .12 .32$ & $117.43 \pm 6.23$ & $\mathrm{p}<0.05$ \\
Duration of effective & $212 \pm 13$ & $117 \pm 16$ & $\mathrm{p}<0.05$ \\
\end{tabular}

Motor Blockade: The onset of motor blockade was clinically earlier in group II but statistically not significant. All patients in both groups had complete motor blockade. The mean duration of motor recovery was shorter in group I than group II and was statistically significant $(p<0.05)$. The above parameters are shown in Table III 
Table-III: Comparison of motor blockade between two groups.

\begin{tabular}{lccc}
\hline Parameter & $\begin{array}{c}\text { Group I } \\
\text { mean } \pm \text { SD }\end{array}$ & $\begin{array}{c}\text { Group II } \\
\text { mean } \pm \text { SD }\end{array}$ & p value \\
\hline $\begin{array}{l}\text { Onset of motor } \\
\text { blockade(sec) }\end{array}$ & $78.8 \pm 6.4$ & $75.4 \pm 8.8$ & $\mathrm{p}>0.05$ \\
$\begin{array}{l}\text { Time required for } \\
\text { motor recovery (min) }\end{array}$ & $91.2 \pm 12.3$ & $112.7 \pm 9.6$ & $\mathrm{p}<0.05$ \\
\hline
\end{tabular}

Maternal and fetal outcome: Mean uterine incision to delivery time and neonatal Apgar score at 1 and 5 minutes were statistically not significant (Table IV).

Table-IV: Maternal and fetal outcome

\begin{tabular}{lccc}
\hline Parameter & Group I & Group II & p value \\
\hline $\begin{array}{l}\text { Uterine incision to } \\
\text { delivery time (sec) }\end{array}$ & $95.3 \pm 9.6$ & $98.8 \pm 6.2$ & $\mathrm{p}>0.05$ \\
Apgar score at 1 min. & $9.4 \pm 0.4$ & $9.58 \pm 0.6$ & $\mathrm{p}>0.05$ \\
Apgar score at 5 min & $9.74 \pm 0.32$ & $9.42 \pm 0.53$ & $\mathrm{p}>0.05$ \\
\hline
\end{tabular}

Hemodynamic Variables: The mean maximum heart rate was significantly more in group II than group I $(\mathrm{p}<0.05)$. The decrease in systolic blood pressure in group II was significantly more than group I $(p<0.05)$. More patients in group II required additional fluid and vasopressors as compared to patients in group I. (Table V). The difference of Spo 2 and respiratory rate was not significant in both the groups.

Table-V: Hemodynamic variables

\begin{tabular}{lccc}
\hline & Group I & Group II & p value \\
\hline $\begin{array}{l}\text { Basal heart rate (min) } \\
\text { Minimal heart rate (min) }\end{array}$ & $95.5 \pm 5.4$ & $96.3 \pm 4.7$ & $\mathrm{p}>0.05$ \\
$\begin{array}{l}\text { Maximal heart rate } \\
\text { (min) }\end{array}$ & $102.34 \pm 3.2$ & $108.38 \pm 4.1$ & $\mathrm{p}<0.05$ \\
$\begin{array}{l}\text { Basal systolic blood } \\
\text { pressure (mm Hg) }\end{array}$ & $118.2 \pm 8.4$ & $117.4 \pm 7.2$ & $\mathrm{p}>0.05$ \\
$\begin{array}{l}\text { Minimal systolic blood } \\
\text { pressure (mm Hg) }\end{array}$ & $102.4 \pm 7.8$ & $91.7 \pm 8.2$ & $\mathrm{p}<0.05$ \\
$\begin{array}{l}\text { Minimal diastolic blood } \\
\text { pressure (mm Hg) }\end{array}$ & $68.7 \pm 3.7$ & $61.8 \pm 4.2$ & $\mathrm{p}<0.05$ \\
$\begin{array}{l}\text { Number of patients } \\
\text { required ephidrine }\end{array}$ & $2(5 \%)$ & $8(20 \%)$ & $\mathrm{p}<0.05$ \\
$\begin{array}{l}\text { Number of patients } \\
\text { required additional } \\
\text { crystaloid }\end{array}$ & $2(5 \%)$ & $6(15 \%)$ & $\mathrm{p}<0.05$ \\
\hline
\end{tabular}

Table-VI: The incidence of adverse effects

\begin{tabular}{lcc}
\hline Adverse effects & $\begin{array}{c}\text { Group I Number } \\
\text { of patients (\%) }\end{array}$ & $\begin{array}{c}\text { Group II Number } \\
\text { of patients (\%) }\end{array}$ \\
\hline Nausea & 0 & $4(10 \%)$ \\
Vomiting & 0 & $2(5 \%)$ \\
Bradycardia & 0 & 0 \\
$\begin{array}{l}\text { Hypotension requiring } \\
\text { treatment }\end{array}$ & $2(5 \%)$ & $8(20 \%)$ \\
Pruritus & $2(5 \%)$ & 0 \\
Shivering & 0 & $2(5 \%)$ \\
Respiratory depression & 0 & 0 \\
\hline
\end{tabular}

\section{Discussion}

Anesthesia related complications accounted for $5.2 \%$ maternal death ${ }^{11}$. The relative risk offatality during general anesthesia is 16 times more than that regional anesthesia ${ }^{12}$. Spinal anesthesia is the preferred method for elective cesarean section as being simple to perform, economical and producing rapid onset of anesthesia with complete muscle muscle relaxation. It carries high efficiency, involves less drug doses, minimal neonatal depression and lesser incidence of aspiration pneumonitis. However, it also produces a fixed duration of anesthesia, lesser control of block height, post dural-puncture headache and hypotension ${ }^{13,14}$. This hypotension may cause maternal morbidity, nausea, vomiting and influence the neonatal wellbeing by reducing utero-placental blood flow ${ }^{15}$. The link between the extent of sympathetic block and the incidence of hypotension has led to numerous attempts at reducing the dose of local anesthetics and also addition of opioids due to their synergistic action with local anesthetics on sensory block without increasing sympathetic block for cesarean section ${ }^{16}$. The aim of this study was to assess the hemodynamics, duration of effective analgesia with the combination of fentanyl and low dose hyperbaric bupivacaine. It is observed that the systolic and diastolic blood pressure were decreased significantly after spinal anesthesia in group II when compared to group I, mostly due to more sympathetic blockade by higher dose of bupivacaine $\mathrm{p}<0.05$. Similar findings were observed by Bogra et $\mathrm{al}^{17}$ and also by Seyedhejaze and Madarekl ${ }^{18}$ wherein they studied by using $8 \mathrm{mg}$ of bupivacaine and 10 microgram of fentanyl for spinal anesthesia 
in cesarean section. The quality of analgesia was assessed by VAS was excellent in the bupivacaine and fentanyl group, similar observations were made by Choi et al. also study done by Ngiam and Chong ${ }^{19}$ who observed that the duration of effective analgesia was significantly prolonged with addition of fentanyl to hyperbaric bupivacaine. Idowu et al ${ }^{20}$ made a study, the result of which is similar to this study. Further, in group I two patients complained of mild pruritus, may be because of side effect of fentanyl, but the etiology of it was not ascertained. Similar findings were observed by Cowan et $\mathrm{al}^{21}$ but the study by Jashri et alobserved no incidence of pruritus. No patients complained of nausea and vomiting may be due to reduction of dose of bupivacaine from $12.5 \mathrm{mg}$ to $10 \mathrm{mg}$ causing less hypotension in bupivacaine with fentanyl group. Negligible incidences of shivering or respiratory depression was observed in both the groups, which were similar to findings of Kang et al.Inthis study, none of the newborn babies had 1 and 5 minutes Apgar score $<8$. Similar observations were made by Belzarena indicating that the dose of fentanyl used may not have a significant effect on the newborn. By reducing the doses of bupivacaine from $12.5 \mathrm{mg}$ to $10 \mathrm{mg}$ and the addition of fentanyl, we have been able todecrease the incidence of episodes of low blood pressure and subsequently poor neonatal outcome.

\section{Conclusion}

Thus, it can be concluded that intrathecal fentanyl helps in reducing the dose of $0.5 \%$ hyperbaric bupivacaine for spinal anesthesia in cesarean section thus reducing the incidence of side effects associated with it. By its synergistic effect with $0.5 \%$ hyperbaric bupivacaine it provides better intraoperative and postoperative analgesia, good hemodynamic stability, less incidence of complications like nausea, vomiting and shivering without compromising the safety of mother and the fetus

Conflict of interest: We have no conflict of interest.

\section{References}

1. John F Butterworth, David C, Mac Key, John D, Wasnick (editors) Morgan and Michails Clinical Anesthesiology. 5th edn, New York. Lange Mc Graw Hill education. 2013 p 852-56.

2. Alan R. Aitkenhead, Iain K Moppett, Jonathan P Thomas Smith and Aitkenheads Text book of Anesthesia. 6th edn. Churchill livingstone ELSEVEIR. UK. p 714-15.

3. Sachan P, Kumar N, Sharma J. Intrathecal clonidine with hyperbaric bupivacaine administered as a mixture and sequentially in cesarean section: A randomized controlled trial. Indian J Anesth. 2014; 58: 287-92.

4. McCrae AF, Wildsmith JA. Prevention and treatment of hypotension during central neural block. Br J Anesth. 1993; 70: 672-80.

5. Hug CC Jr, Murphy MR. Tissue redistribution of fentanyl and termination of its effects in rat. Anesthesiology. 1981; 55: 369-75.

6. Jadon A. Complications of regional and general anesthesiain obstetric practice. Indian $\mathrm{j}$ Anesth. 2010;54: 415-20.

7. Moller LA, Covino BG. Effect of progesterone on the cardiac electrophysiologic alterations produced by ropivacaine and bupivacaine. Anesthesiology. 1992; 77: 735-41.

8. Akkamahadevi P, Srinivas H, Siddesh A, et al. Comparison of efficacy of sufentanyl and fentanyl with low concentration of bupivacaine for combined spinal epidural labour analgesia. Indian J Anesth. 2012; 56: 365-9.

9. Tan PH, Chia YY, Lo Y, Lee TH. Intrathecal bupivacaine with morphine or neostigmine for postoperative analgesia after total knee replacement. Can J Anesth. 2001; 48: (6): 551-6.

10. Ben- David B, Solomon E, Levin H, et al. Intrathecal fentanyl with small dose dilute bupivacaine: Better anesthesia with prolonging recovery. Anes Analg. 1997; 85: 560-5. 
11. Panchal S, Arria AM, Labhsesetwar SA; Maternal mortality during hospital admission for delivery; A retrospective analysis using a state maintained database. Anesth Analg. 2001; 93: $134-41$

12. Hawkings JL, Koonin LM, Palmer SK.et al: Anesthesia related deaths during obstetric delivery in the United States. 1979-1990. Anesthesiology 1999; 86: 277-84.

13. Rout CC, Rocke DA, Levin J, et al. A reevaluation of the role of crystaloid preload in the prevention of hypotension associated with spinal anesthesia for elective cesarean section. Anesthesiology. 1993; 79: 262-9.

14. Caplan RA, Ward RJ, Posner $\mathrm{K}$, et al. Unexpected cardiac arrest during spinal anesthesia: A closed claims analysis of predisposing factors. Anesthesiology. 1988; 68: 5-11.

15. De Santiago J. The effect of pregnant uterus on the extradural venous plexus in the supine and lateral positions, as determined by magnetic resonance imaging. Br j Anesth. 1997; 78: 317.

16. Kaur $M$, Katyal $S$, kathuria $S$, et al. A comparative evaluation of intrathecal bupivacaine alone, sufentanyl or butrophanol in combination with bupivacaine for endoscopic urological surgery. Saudi J Anesth. 2011; 5: 202-7.
17. Bogra J, Arora N, Srivastava P. Synergistic effect of intrathecal fentanyl and bupivacaine in spinal anesthesia for cesarean section. BMC Anesthesiol. 2005:5:5.

18. Seyedhejaji M , Madarek E. Effect of small dose bupivacaine -fentanyl in spinal anesthesia on hemodynamic nausea and vomiting in cesarean section. Park J Med Sci. 2007; 23: $747-50$

19. Ngiam Sk, Chong JL. The addition of intrathecal sufentanyl and fentanyl to bupivacaine for cesarean section. Singapore Med j. 1998; 39: 290-94

20. Idowu OA, Sanusi AA, Eyelade OR. Effects of intrathecally administered fentanyl on duration of analgesia in patients undergoing spinal anesthesia for elective cesarean section. Afr $\mathbf{J}$ Med Sci. 2011; 40: 213-9

21. Cowan CM, Kendall JB, Barclay PM, et al. Comparison of intrathecal fentanyl and diamorphine in addition to bupivacaine for cesarean section under spinal anesthesia. $\mathrm{Br} \mathrm{J}$ Anesth. 2002; 89: 452-8. 